\title{
Identification of Species of Nontuberculous Mycobacteria Clinical Isolates from 8 Provinces of China
}

\author{
Haican Liu, ${ }^{1}$ Lulu Lian, ${ }^{1,2}$ Yi Jiang, ${ }^{1}$ Mingxiang Huang, ${ }^{3}$ Yunhong Tan, ${ }^{4}$ \\ Xiuqin Zhao, ${ }^{1}$ Jingrui Zhang, ${ }^{1}$ Qin Yu, ${ }^{1,2}$ Jiao Liu, ${ }^{1}$ Haiyan Dong, ${ }^{1}$ Bing Lu, ${ }^{1}$ \\ Yimou $\mathrm{Wu}^{2}$ and Kanglin Wan ${ }^{1,2}$
${ }^{1}$ State Key Laboratory for Infectious Disease Prevention and Control, Collaborative Innovation Center for Diagnosis and Treatment of Infectious Diseases, National Institute for Communicable Disease Control and Prevention, Chinese Center for Disease Control and Prevention, Beijing 102206, China
${ }^{2}$ Pathogenic Biology Institute, University of South China, Hengyang, Hunan 421001, China
${ }^{3}$ Fuzhou Pulmonary Hospital (Clinical Teaching Hospital of Fujian Medical University), Fuzhou, Fujian 350008, China \\ ${ }^{4}$ Hunan Institute for Tuberculosis Control/Hunan Chest Hospital, Changsha, Hunan 410013, China
}

Correspondence should be addressed to Yimou Wu; yimouwu@sina.com and Kanglin Wan; wankanglin@icdc.cn

Received 23 June 2016; Accepted 29 September 2016

Academic Editor: Ruxana Sadikot

Copyright (C) 2016 Haican Liu et al. This is an open access article distributed under the Creative Commons Attribution License, which permits unrestricted use, distribution, and reproduction in any medium, provided the original work is properly cited.

\begin{abstract}
Pulmonary diseases caused by nontuberculous mycobacteria (NTM) are increasing in incidence and prevalence worldwide. In this study, we identified NTM species of the clinical isolates from 8 provinces in China, in order to preliminarily provide some basic scientific data in the different species and distribution of NTM related to pulmonary disease in China. A total of 523 clinical isolates from patients with tuberculosis (TB) diagnosed clinically from 2005 to 2012 were identified to the species using conventional and molecular methods, including multilocus PCR, $r p o B$ and $h s p 65$ PCR-PRA, $h s p 65, r p o B$, and 16S-23S internal transcribed spacer region sequencing. The isolates were identified into 3 bacterium genera, including NTM, Gordonia bronchialis, and Nocardia farcinica, and, for the 488 NTM isolates, 27 species were identified. For all the 27 species of NTM which were found to cause pulmonary infections in humans, the most prevalent species was M. intracellulare, followed by M. avium and M. abscessus. And seven other species were for the first time identified in patients with TB in China. NTM species identification is very important for distinguishing between tuberculosis and NTM pulmonary diseases, and the species diversity drives the creation of diverse and integrated identification methods with higher accuracy and efficacy.
\end{abstract}

\section{Introduction}

The Mycobacterium genus consists of species belonging to the Mycobacterium tuberculosis complex (MTBC), Mycobacterium leprae, and nontuberculous mycobacteria (NTM). NTM are environmental opportunistic pathogens in some cases $[1,2]$ and nonpathogenic in others $[1,3]$. To date, more than 160 NTM species have been recognized, while many others await classification [4]; approximately one-third have been associated with diseases in humans [4]. The importance of NTM has recently increased and the pathogenic roles of many of these mycobacteria have been clearly defined [5]. Known reasons for this include (1) raising awareness, gaining more and more interests for these genera; (2) increased number of immunosuppressed patients including HIV; (3) increased number of patients with preexisting lung disease; and (4) mostly increased distribution of methods to detect NTM species $[6,7]$.

Tuberculosis (TB) remains a major public health problem in China. Identification of NTM has been conducted only in a few clinical laboratories in China, so misdiagnosis and incorrect treatment are commonly given to the patients infected with NTM. As some of the NTM species are natively insensitive to the commonly used antituberculosis drugs, the NTM infected patients may be treated as drug-resistant TB, which result in some of the TB patients getting misdiagnosis and inappropriate therapy [8]. Once the anti-TB therapy fails, the treatment of NTM infection might be delayed several 
TABLE 1: The distribution of clinical NTM strains throughout 8 Chinese provinces.

\begin{tabular}{lccc}
\hline Province & $\begin{array}{c}\text { Mycobacterium } \\
\text { strain number }\end{array}$ & NTM number & $\begin{array}{c}\text { Rate of NTM in } \\
\text { Mycobacterium } \\
(\%)\end{array}$ \\
\hline Anhui & 180 & 7 & 3.9 \\
Fujian & 3139 & 405 & 12.9 \\
Gansu & 623 & 43 & 6.9 \\
Hunan & 1133 & 51 & 4.5 \\
Jiangxi & 93 & 4 & 4.3 \\
Inner Mongolia & 103 & 4 & 3.9 \\
Sichuan & 44 & 2 & 4.5 \\
Xinjiang & 140 & 7 & 5.0 \\
\hline Total & 5455 & 523 & 9.6 \\
\hline
\end{tabular}

NTM: nontuberculosis mycobacterium.

months or even more. That is why now increased awareness of NTM identification is important. Distinguishing the diseases caused by different pathogens to avoid misdiagnosis allows for accurate treatment. American Thoracic Society documents state that NTM should generally be identified to the species level [5]. In the current study, we collected 523 clinical NTM isolates from 8 provinces in China and identified them to species or subspecies level. These data may preliminarily provide an insight into the different species and distribution of NTM related to pulmonary disease in China and help to prevent treatment failure by underscoring the importance of differentiating mycobacterial species.

\section{Materials and Methods}

2.1. Ethics Statement. This study was approved by the Ethics Committee of the National Institute for Communicable Disease Control and Prevention, Chinese Center for Disease Control and Prevention. All participants provided written informed consent.

2.2. Mycobacterial Isolates. From 2005 to 2012, 523 clinical isolates were provided by the province's TB hospital or center for TB control in 8 provinces or autonomous regions, which include Anhui, Fujian, Gansu, Hunan, Jiangxi, Inner Mongolia, Sichuan, and Xinjiang, and conserved at the National Institute for Communicable Disease Control and Prevention, Chinese Center for Disease Control and Prevention, Beijing, China, for NTM species identification. Table 1 and Figure 1 show the distribution of these clinical strains in detail. All of the isolates, isolated from sputum of TB patients, were primarily identified as NTM by each province's TB hospital laboratory using conventional biochemical testing with p-nitrobenzoic acid/2-thiophene carboxylic acid hydrazide (PNB/TCH) media and incubated at $37^{\circ} \mathrm{C}$ for $3 \sim 4$ weeks following a standard protocol $[9,10]$.

2.3. DNA Sample Preparation. For the DNA extraction, a loopful of organisms grown on Löwenstein-Jensen (L-J) medium incubated at $37^{\circ} \mathrm{C}$ for 3-4 weeks was suspended in $200 \mu \mathrm{L}$ of $\mathrm{pH} 8.0$ TE buffer $(10 \mathrm{mM}$ Tris- $\mathrm{HCl} ; 1 \mathrm{mM}$ ethylenediaminetetraacetic acid). The bacterial cells were lysed with lysozyme and the genomic DNA was isolated using cetyltrimethylammonium bromide $[11,12]$.

2.4. Multilocus PCR. According to Huard et al. [13], the MTBC PCR typing panel using 7 primer pairs amplifying within the loci $16 S$ rRNA, Rv0577, IS1561', Rv1510, Rv1970, $R v 3877 / 8$, and $R v 3120$ results in pattern of amplification products from all of the reactions that allow differentiation of NTM from MTBC subspecies by agarose gel electrophoresis. PCR amplifications were performed using a program with an initial denaturation step of $5 \mathrm{~min}$ at $94^{\circ} \mathrm{C}$ followed by 35 cycles of $1 \mathrm{~min}$ at $94^{\circ} \mathrm{C}, 1 \mathrm{~min}$ at $60^{\circ} \mathrm{C}$, and $1 \mathrm{~min}$ at $72^{\circ} \mathrm{C}$ and ending with a final elongation step of $10 \mathrm{~min}$ at $72^{\circ} \mathrm{C}$. The PCR products and a $100 \mathrm{bp}$ ladder (Beijing CoWin Biotech Co., Ltd., Beijing, China) were visualized using $2 \%$ agarose gel electrophoresis and ethidium bromide (EB) staining.

2.5. Amplification of $r p o B$ and hsp65 Partial DNA. A specific region of the $r p o B$ gene was amplified using primers $r p o B$ $\mathrm{F}\left(5^{\prime}\right.$-TCAAGGAGAAGCGCTACGA- $\left.3^{\prime}\right)$ and $r p o B \mathrm{R}\left(5^{\prime}\right.$ ATGTTGATCAGGGTCTGC- $\left.3^{\prime}\right)$, resulting in a 360 bp PCR product $[14,15]$. Primers Tbll $\left(5^{\prime}\right.$-ACCAACGATGGTGTGTCCAT $\left.-3^{\prime}\right)$ and Tb12 (5' -CTTGTCGAACCGCATACCCT$3^{\prime}$ ) amplified a $441 \mathrm{bp}$ fragment between positions 398 and 836 of the published hsp65 gene $[16,17]$. The composition of the PCR mixture $(50 \mu \mathrm{L})$ was $25 \mu \mathrm{L}$ of $2 \mathrm{x}$ Taq MasterMix (Beijing CoWin Biotech Co., Ltd.), $2 \mu \mathrm{L}$ of each primer at $10 \mu \mathrm{M}, 5 \mu \mathrm{L}$ of DNA-containing supernatant, and $16 \mu \mathrm{L}$ of $\mathrm{ddH}_{2} \mathrm{O}$. The reaction was subjected to 35 cycles of amplification $\left(1 \mathrm{~min}\right.$ at $94^{\circ} \mathrm{C}, 1 \mathrm{~min}$ at $60^{\circ} \mathrm{C}$, and $1 \mathrm{~min}$ at $72^{\circ} \mathrm{C}$ ), followed by 10 min of extension at $72^{\circ} \mathrm{C}$. The PCR products and a $100 \mathrm{bp}$ ladder (Beijing CoWin Biotech Co., Ltd.) were visualized using 2\% agarose gel electrophoresis and EB staining. The PCR products were purified using a Quick DNA Purification Kit (Beijing CoWin Biotech Co., Ltd.).

2.6. PRA-hsp65 [17] and PRA-rpoB [15] Methods and Analysis. The purified PCR products were digested with restriction enzyme (Takara Biotechnology [Dalian] Co., Ltd.). The hsp65 gene PCR products were digested with BstP I $(1 \mu \mathrm{L}$ of Bst $\mathrm{P}$ I, $15 \mu \mathrm{L}$ of DNA, $2 \mu \mathrm{L}$ of $10 \mathrm{x} \mathrm{H}$ buffer, and $2 \mu \mathrm{L}$ of $\mathrm{ddH}_{2} \mathrm{O}$ at $60^{\circ} \mathrm{C}$ for $\left.2 \mathrm{~h}\right)$ and Hae III $(1 \mu \mathrm{L}$ of Hae III, $15 \mu \mathrm{L}$ of DNA, $2 \mu \mathrm{L}$ of $10 \mathrm{x} \mathrm{M}$ buffer, and $2 \mu \mathrm{L}$ of $\mathrm{ddH}_{2} \mathrm{O}$ at $37^{\circ} \mathrm{C}$ for $2 \mathrm{~h}$ ). For $r p o B$ gene's PCR products, the reactions contained $M s p$ I $(1 \mu \mathrm{L}$ of $M s p$ I, $15 \mu \mathrm{L}$ of DNA, $2 \mu \mathrm{L}$ of $10 \mathrm{x}$ T buffer, and $2 \mu \mathrm{L}$ of $0.1 \% \mathrm{BSA})$ and Hae III ( $1 \mu \mathrm{L}$ of Hae III, $15 \mu \mathrm{L}$ of DNA, $2 \mu \mathrm{L}$ of $10 \mathrm{x} \mathrm{M}$ buffer, and $2 \mu \mathrm{L}$ of $\mathrm{ddH}_{2} \mathrm{O}$ ) and both were incubated at $37^{\circ} \mathrm{C}$ for $2 \mathrm{~h}$. The resulting restriction fragments were separated using electrophoresis in a $4 \%$ agarose gel (MetaPhor ${ }^{\circledR}$ Agarose, LONZA) with a 20 bp ladder (Takara Biotechnology [Dalian] Co., Ltd.) as molecular standard. The gels were stained with $\mathrm{EB}$ and then photographed using a ChemiDoc ${ }^{\mathrm{TM}}$ XRS+ System (Bio-Rad Laboratories, Inc., Hercules, USA). The restriction fragment sizes were estimated using Image Lab software (Bio-Rad Laboratories, 


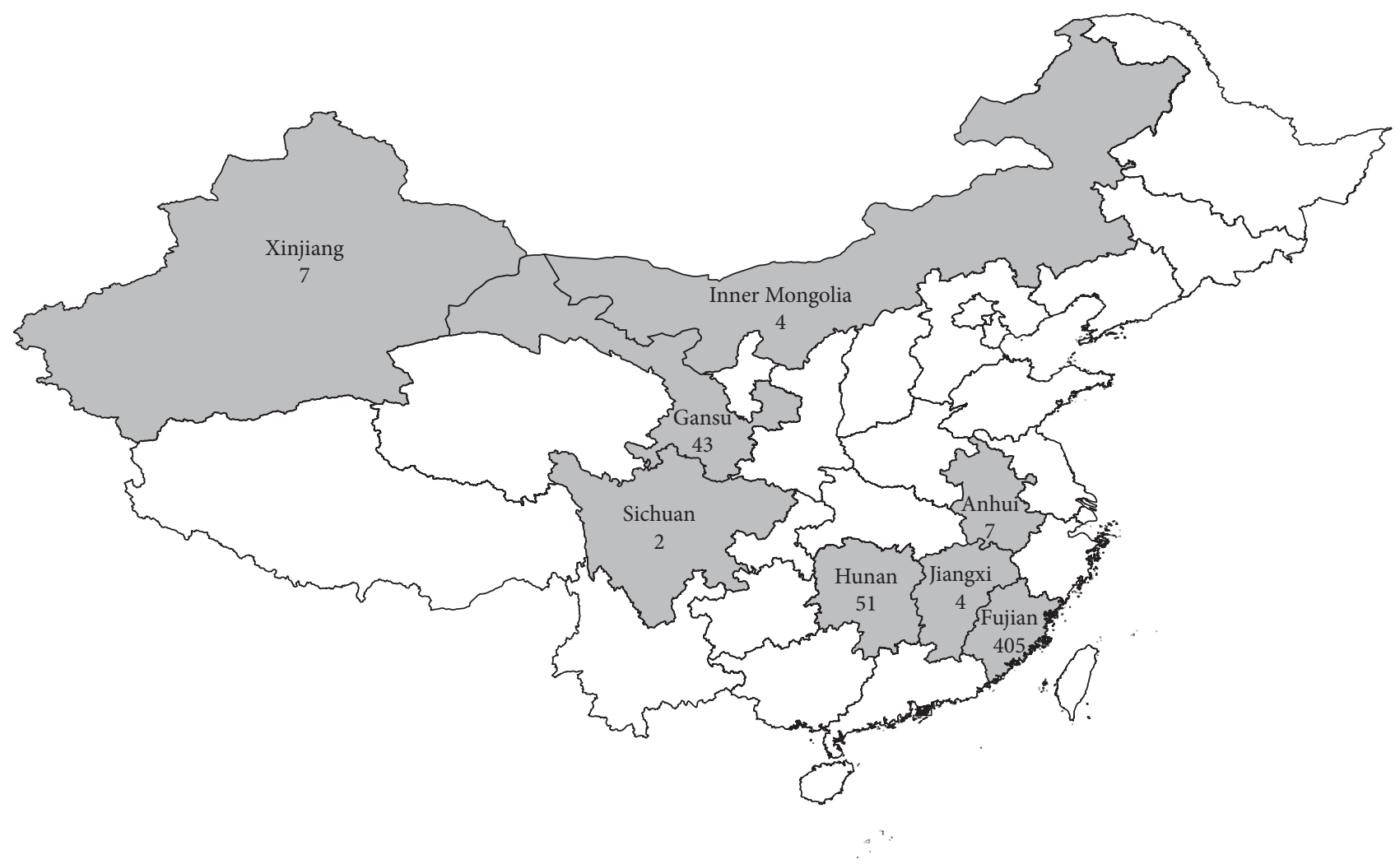

FIgURE 1: Distribution of clinical isolate strains in the 8 provinces. There are different colors in the different regions. The numbers of isolates and the constituent ratios were marked under the corresponding provinces.

Inc., Hercules, USA). Species identification was confirmed according to restriction fragment size [16-25].

2.7. PCR Sequencing and Multisequence Alignment. When correct identification by PRA was impossible or discordant results were obtained between PRA and phenotypic methods, gene sequencing was performed to properly identify the mycobacterial species [26]. To identify the isolates to the species level, we firstly sequenced partial hsp65 sequences of the strains that were not identified by PRA and then for the other strains $<97 \%$ matched of the existing $h s p 65$ sequences, also sequencing the partial $r p o B$ gene and the $16 \mathrm{~S}-23 \mathrm{~S}$ internal transcribed spacer (ITS) region, using the previously published primers and methods $[19,27,28]$. The PCR products were sequenced by Beijing Tsingke Bio Tech Co., Ltd. (Beijing, China). The obtained sequences were compared with those in the GenBank (National Center for Biotechnology Information: http://www.ncbi.nlm.nih.gov/) DNA sequence database, and species identification was confirmed if a 97\% match was achieved $[17,29]$.
2.8. Statistical Analysis. Data are presented as the frequencies for NTM species in 8 provinces. The $\chi^{2}$ test was used to compare differences in proportions; $P<0.05$ was considered statistically significant. All statistical analyses were performed using statistical software (SPSS 16.0; SPSS; Chicago, IL).

\section{Results}

A total of 523 clinical isolates primarily identified using L$\mathrm{J}$ and $\mathrm{PNB} / \mathrm{TCH}$ tests at the local province's TB hospital laboratories of 8 provinces in China were confirmed to be NTM with the same results of PNB/TCH tests and Multilocus PCR. And according to the results of PRA- $h s p 65$ and PRA$r p o B$ screening, it was shown that, using the 2 gene PRA patterns (Figure 2), 302 (57.74\%; 302/523) clinical isolates were identified to 13 species of NTM, while the remaining $221(42.26 \% ; 221 / 523)$ isolates presented unknown restriction patterns or different patterns that were not comparable to those of the reference strains (Table 3 ). Figure 3 shows the 


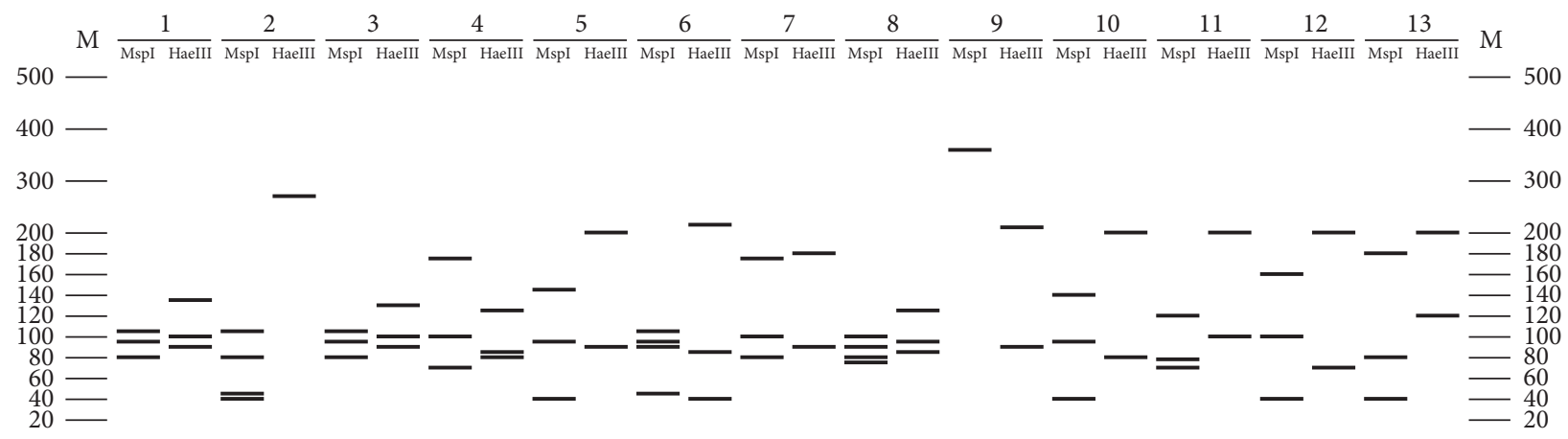

(a) PRA-rpoB MspI-HaeIII

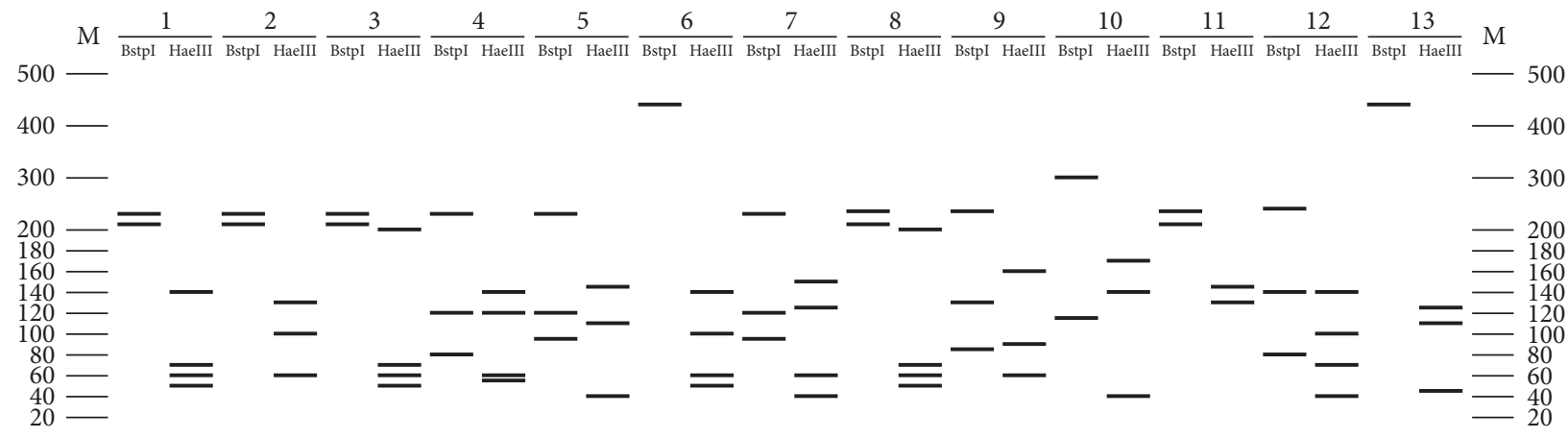

(b) PRA-hsp65 BstpI-HaeIII

FIgURE 2: The PRA- $h s p 65$ gene and PRA-rpoB gene patterns of 13 different species of NTM in our study. M: 20 bp DNA ladder; $1:$ M. abscessus; 2: M. avium; 3: M. chelonae; 4: M. fortuitum; 5: M. gordonae; 6: M. holsaticum; 7: M. intracellulare; 8: formerly M. massiliense; 9: M. monacense; 10: M. neoaurum; 11: M. seoulense; 12: M. shimoidei; and 13: M. szulgai.

representative PRA- $h s p 65$ and PRA-rpoB patterns of 13 different species of NTM. Herein, the remaining 221 isolates were further analyzed by determination of the nucleotide sequence of the $h s p 65, r p o B$, and ITS genes (the accession numbers of these sequences can be found in the Supplementary Material available online at http://dx.doi.org/10.1155/2016/2153910). A total of $88.69 \%(196 / 221)$ were identified to the species level according to the criterion of the first 97\% distinct hsp65 sequence match, while the other 25 (11.31\%; 25/221) isolates were identified to the species level using $r p o B$ and ITS sequencing (Figure 4).

In summary, we obtained 29 species (Table 2), including 27 NTM (488 strains), one Gordonia bronchialis (2 strains), and one Nocardia farcinica (32 strains), and for the 27 NTM species they were identified as belonging to the Mycobacterium genus (Table 2), including 6 slowly growing scotochromogenic species (Runyon Groups II), 11 slowly growing nonpigmented species (Runyon Groups III), and 10 rapidly growing species (Runyon Groups IV).

Table 2 also shows the frequency of the different species identified from the 523 isolates using molecular methods. As in Fujian and Hunan provinces, $M$. intracellulare and $M$. avium account for $56.60 \%$, more than half of the total 523 isolates. In these 8 provinces, the proportion of $M$. avium and $M$. intracellulare (106 strains and 206 strains, resp.) was $59.66 \%$. According to Table 1, there were 404 (12.87\%) NTM in these 3139 strains in Fujian, followed by Hunan, and 1133 Mycobacterium strains including 50 NTM (4.41\%). Using
SPSS 16.0 software package, we found that the difference between NTM and MTB species distribution in Hunan and Fujian province is statistically significant $\left(\chi^{2}=62.69, P=\right.$ 0.00 ) according to 0.05 significance level. We may consider that the NTM infection rate of Fujian is higher than that of Hunan province.

\section{Discussion}

Recently the prevalence of NTM diseases in China is rising as the incidence of the pulmonary disease which was predisposed to NTM is increasing $[30,31]$, and the coinfection of HIV also contributed to this increase. The clinical symptoms and signs of NTM caused diseases are often hard to differentiate from those of MTBC-induced diseases, and the clinical NTM isolates are often of natural resistance to drugs that for TB infection treatment are linked to inadequate treatment in the public health system and the private hospital system, even in TB hospitals [32]. Also, the management and treatment of infected patients, in addition to the implemented epidemiological control methods, must reflect the encountered specific mycobacterial species [33]; therefore, it is important to accurately identify the NTM infections. Furthermore, Although there are diagnostic criteria of NTM diseases in the American Thoracic Society documents, there is not enough known about most other NTM species to ensure that these diagnostic criteria are universally applicable 


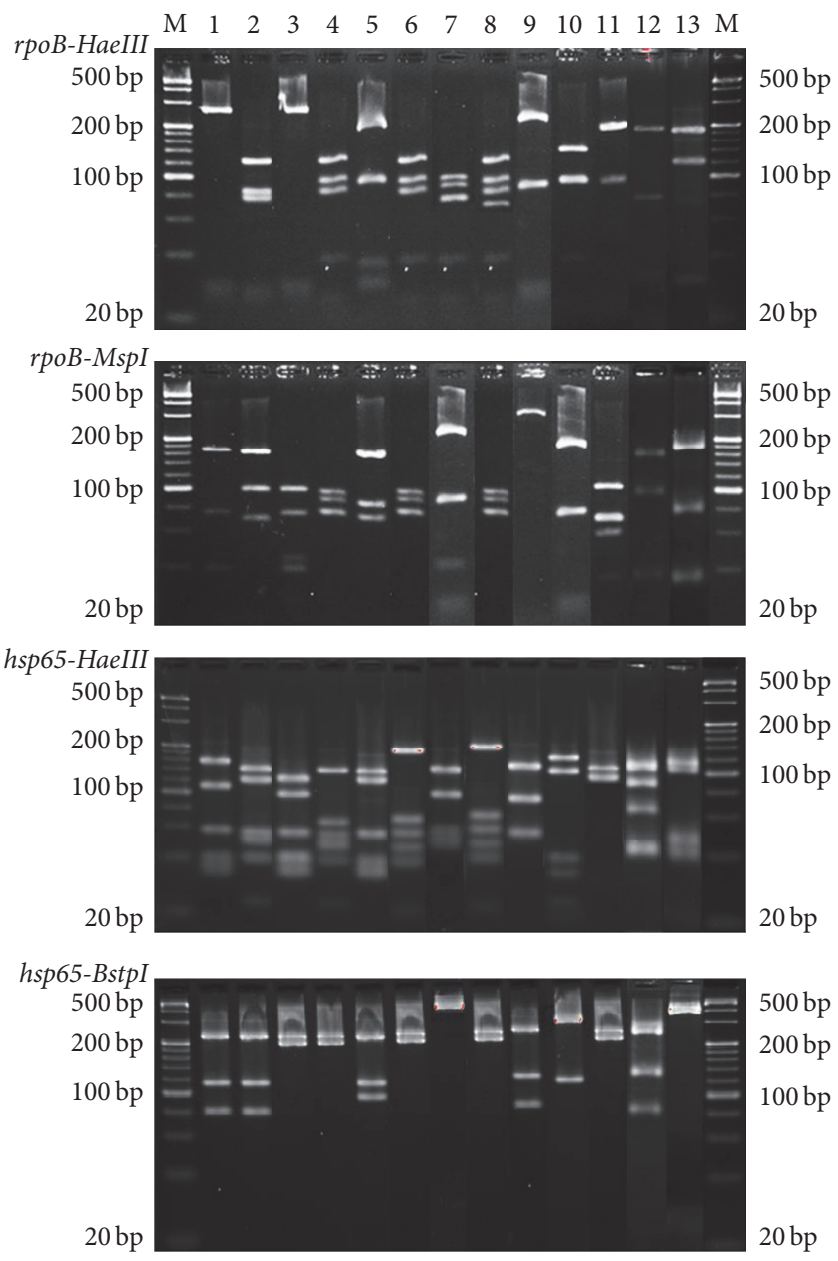

FIgURE 3: The results on gel electrophoresis of different species of NTM with PRA-hsp65 and PRA-rpoB. M: 20 bp DNA ladder; 1: HN11051, M. gordonae; 2: HN11052, M. fortuitum; 3: HN1053, M. avium; 4: HN11054, M. abscessus; 5: FJ05232, M. intracellulare; 6: FJ10024, M. chelonae; 7: FJ10038, M. holsaticum; 8: FJ10101, formerly M. massiliense; 9: FJ10130, M. monacense; 10: HN11058, M. neoaurum; 11: FJ10157, M. seoulense; 12: FJ12019, M. shimoidei; and 13: FJ12159, M. szulgai.

to all NTM respiratory pathogens [5]. So much more research of NTM infections should be performed.

It is well known that NTM are ubiquitous environmental microorganisms that can be found in a variety of ecosystems [34]. In the selected 8 provinces, most of isolates were collected in Fujian and Hunan province. Fujian lies in the southern coast of China, and the local subtropical climate in this area may affect the NTM recovery. We analyzed the difference between the species distribution in Hunan and Fujian province that is statistically significant $\left(\chi^{2}=62.69\right.$, $P=0.00$ ) according to 0.05 significance level. We may consider that NTM incidence of Fujian province is more than that of Hunan. One hypothesis is that water exposure is important, also sea-water exposure [35]. And the fact that Fujian has a long sea border may potentially explain the significant differences found in the isolation frequency in comparison to that of the Hunan province since water exposure including sea water may be relevant for prevalence of different NTM strains. In the future, we will try to collect more Mycobacterium isolates form different provinces and to identify more NTM species, so that comparisons between the species distribution in different provinces could be made.

NTM can cause disseminated diseases in severely immunocompromised patients and affect organs such as the skin and soft tissues $[5,26]$. These strains were isolated from sputum of TB patients; maybe these NTM can cause lung infections. M. marseillense, $M$. saskatchewanense, $M$. seoulense, M. kumamotonense, $M$. stomatepiae, and $M$. mantenii were first identified in patients with TB in China. More and more lung infection-causing NTM species are being found and need to be confirmed clinically. In contrast with MTBC members, NTM are free-living and ubiquitously distributed microorganisms with diverse abilities to cause disease in human beings and have emerged in the past few decades as being frequently associated with HIV coinfection [5]. NTM species are of great significance for control and prevention of TB.

Two other genera, Nocardia and Gordonia, were also identified in these isolates as well, but their findings were not differentiated using traditional identification methods 


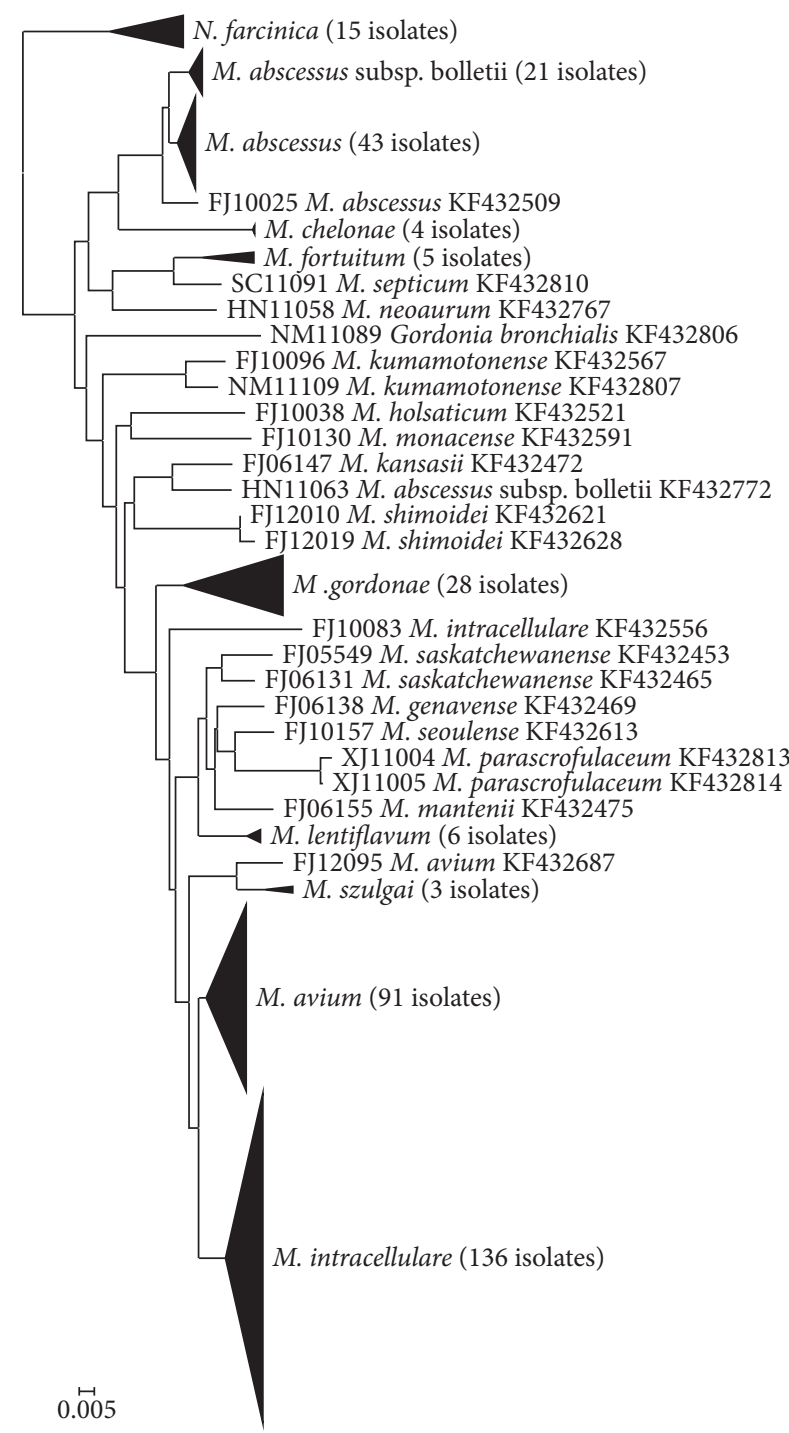

(a) Partial $h s p 65$ gene

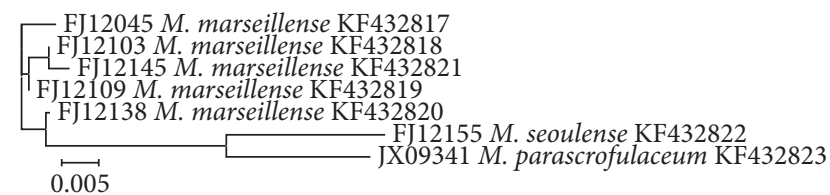

(b) ITS gene

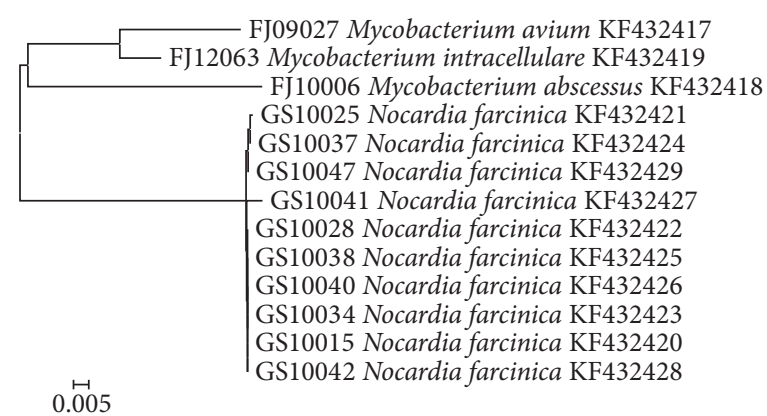

(c) $r p o B$ gene

FIGURE 4: The phylogenetic trees (N-J) constructed by the gene sequences.

such as acid-fast stains, $\mathrm{PNB} / \mathrm{TCH}$ differential media, and multilocus PCR. Furthermore, although N. farcinica and G. bronchialis could be discriminated from the mycobacteria species using hsp65 sequencing. The question is why Nocardia spp. are gram-positive, partially acid-fast, opportunistic pathogens. G. bronchialis is a slightly acid-fast organism that has been identified in both the sputum of patients with pulmonary disease and the soil [36]. As such, special and rapid methods should be used to identify partially or slightly acid-fast species. A total of $33 \mathrm{~N}$. farcinica and 2 
TABLE 2: Frequency of 29 different species identified by molecular methods from 523 isolates.

\begin{tabular}{|c|c|c|c|c|c|c|c|c|c|c|}
\hline Genus $(n)$ & Species & Anhui & Fujian & Gansu & Hunan & Jiangxi & Neimeng & Sichuan & Xinjiang & Overall $n(\%)$ \\
\hline \multirow[t]{15}{*}{ Gordonia (2) } & Gordonia bronchialis & & 1 & & & & 1 & & & $2(0.38)$ \\
\hline & M. abscessus & & 55 & & 5 & & & & & $60(12.30)$ \\
\hline & M. avium & 2 & 88 & & 13 & 2 & & 1 & & $106(21.72)$ \\
\hline & M. chelonae & & 1 & 5 & & & & & & $6(1.23)$ \\
\hline & M. colombiense & & 1 & & & & & & 2 & $3(0.61)$ \\
\hline & M. fortuitum & & 9 & & 2 & & & & & $11(2.25)$ \\
\hline & M. genavense & & 1 & & & & & & & $1(0.20)$ \\
\hline & M. gordonae & & 28 & 4 & 2 & & & & & $34(6.97)$ \\
\hline & M. holsaticum & & 1 & & & & & & & $1(0.20)$ \\
\hline & M. intracellulare & 4 & 173 & 2 & 22 & & 2 & & 3 & $206(42.21)$ \\
\hline & M. kansasii & & 1 & & 1 & & & & & $2(0.41)$ \\
\hline & M. kumamotonense & & 1 & & & & 1 & & & $2(0.41)$ \\
\hline & M. lentiflavum & & 6 & & & & & & & $6(1.23)$ \\
\hline & M. mantenii & & 1 & & & & & & & $1(0.20)$ \\
\hline & M. marseillense & & 5 & & & & & & & $5(1.02)$ \\
\hline \multirow{13}{*}{ NTM (488) } & Formerly M. massiliense & 1 & 19 & & 2 & & & & & $22(4.51)$ \\
\hline & M. monacense & & 1 & & & & & & & $1(0.20)$ \\
\hline & M. neoaurum & & & & 2 & & & & & $2(0.41)$ \\
\hline & M. parascrofulaceum & & & & & 1 & & & 2 & $3(0.61)$ \\
\hline & M. phocaicum & & & & 1 & & & & & $1(0.20)$ \\
\hline & M. saskatchewanense & & 2 & & & & & & & $2(0.41)$ \\
\hline & M. seoulense & & 2 & & & & & & & $2(0.41)$ \\
\hline & M. septicum & & 1 & & & & & 1 & & $2(0.41)$ \\
\hline & M. setense & & & 1 & & & & & & $1(0.20)$ \\
\hline & M. shimoidei & & 2 & & & & & & & $2(0.41)$ \\
\hline & M. stomatepiae & & 1 & & & & & & & $1(0.20)$ \\
\hline & M. szulgai & & 3 & & & & & & & $3(0.61)$ \\
\hline & M. triplex & & 2 & & & & & & & $2(0.41)$ \\
\hline Nocardia (32) & N. farcinica & & & 31 & 1 & 1 & & & & $33(6.31)$ \\
\hline
\end{tabular}

NTM: nontuberculous mycobacteria.

G. bronchialis strains were differentiated from the suspected NTM by PRA and sequencing, which may lead to greater diagnostic accuracy and a more effective treatment system. PRA and sequencing methods are accurate and rapid but costly, which creates a high burden for China, a developing country.

PRA-hsp65 and PRA-rpoB are simple, rapid, and accurate to a certain extent and have been routinely used to identify mycobacteria. Here we used them to identify the obtained 300 clinical isolates. Because of the limitations of PRA and the unknown restriction pattern, the remaining 221 isolates were further analyzed using nucleotide sequencing of the $h s p 65$, $r p o B$, and ITS genes. Due to $h s p 65$ gene hypervariability, sequence analysis of the Telenti fragment (441 bp) has become routine in taxonomical studies and in the identification of clinical Mycobacterium isolates [37]. The $r p o B$ and ITS gene sequencing processes are auxiliary tools. Strain diversity results in the need for diverse identification methods and integrated solutions that create more accurate and effective results.
In this study we think there were limitations, for example, in the sampling of strains from some provinces. We collected clinical positive acid-fast strains that were isolated from sputum samples of clinically diagnosed TB patients in each province. But for some reasons, such as China being very big and different provinces' conditions, there were significant differences among the clinical isolates collected from different provinces (Table 1). Though the strain data had no representativeness of the samples in China, it still could preliminarily provide some basic scientific data in the different species and distribution of NTM related to pulmonary disease and some new NTM species associated to pulmonary disease. And, a lot of work still needs to be done in the future.

In summary, we identified 27 species of NTM, including M. marseillense, M. saskatchewanense, M. seoulense, M. kumamotonense, M. stomatepiae, M. mantenii, and G. bronchialis, that were first identified in patients with tuberculosis diagnosed clinically. And combining use of multilocus PCR, PRA- $h s p 65$, and PRA-rpoB and genes sequencing methods can efficiently identify NTM isolates. This study can 
TABLE 3: Fragment lengths (base pairs) of the isolates with the patterns using the PRA-rpoB and PRA-hsp65 methods.

\begin{tabular}{|c|c|c|c|c|c|c|c|}
\hline \multirow{2}{*}{ Number } & \multirow{2}{*}{ Species } & \multicolumn{2}{|c|}{ PRA $^{\mathrm{d}}-r p o B$} & \multicolumn{2}{|c|}{$\mathrm{PRA}^{\mathrm{d}}-h s p 65$} & \multirow{2}{*}{ Species $(n)$} & \multirow{2}{*}{ Total } \\
\hline & & MspI & HaeIII & BstpI & HaeIII & & \\
\hline 1 & M. abscessus & $105,95,80$ & $135,100,90$ & 230,210 & $140,70,60,50$ & M. abscessus (44) & 44 \\
\hline 2 & M. avium & $105,80,45,40$ & 270 & 230,210 & $130,100,60$ & M. avium (73) & 73 \\
\hline 3 & M. chelonae & $105,95,80$ & $130,100,90$ & 230,210 & $200,70,60,50$ & M. chelonae (1) & 1 \\
\hline 4 & M. fortuitum & $175,100,70$ & $125,85,80$ & $230,120,80$ & $140,120,60,55$ & M. fortuitum (8) & 8 \\
\hline \multirow[t]{3}{*}{5} & M. gordonae ${ }^{\mathrm{a}}$ & $145,95,40$ & 200,90 & $230,120,95$ & $145,110,40$ & M. gordonae (2) & 12 \\
\hline & & $145,95,40$ & $210,95,90$ & $235,120,85$ & $160,115,60$ & M. gordonae (4) & \\
\hline & & $175,80,40$ & 270 & $230,120,80$ & $160,110,60$ & M. gordonae (6) & \\
\hline 6 & M. holsaticum & $105,95,90,45$ & $215,85,40$ & 440 & $140,100,60,50$ & M. holsaticum (1) & 1 \\
\hline \multirow[t]{3}{*}{7} & M. intracellulare ${ }^{\mathrm{b}}$ & $175,100,80$ & 180,90 & $230,120,95$ & $150,125,60,40$ & M. intracellulare (105) & 154 \\
\hline & & $180,90,80$ & 185,105 & $240,120,100$ & $140,125,60,40$ & M. intracellulare (2) & \\
\hline & & 180,90 & $180,90,80$ & $240,120,100$ & $140,125,60,40$ & M. intracellulare (47) & \\
\hline 8 & Formerly M. massiliense & $100,90,80,75$ & $125,95,85$ & 235,210 & $200,70,60,50$ & Formerly $M$. massiliense (4) & 4 \\
\hline 9 & M. monacense & 359 & 210,90 & $235,130,85$ & $160,90,60$ & M. monacense (1) & 1 \\
\hline 10 & M. neoaurum & $140,95,40$ & 200,80 & 300,115 & $170,140,40$ & M. neoaurum (1) & 1 \\
\hline 11 & M. seoulense & $120,78,70$ & 200,100 & 235,210 & 145,130 & M. seoulense (1) & 1 \\
\hline 12 & M. shimoidei & $160,100,40$ & 200,70 & $240,140,80$ & $140,100,70,40$ & M. shimoidei (1) & 1 \\
\hline 13 & M. szulgai & $180,80,40$ & 200,120 & 440 & $125,110,45$ & M. szulgai (1) & 1 \\
\hline 14 & Not identified & $-^{c}$ & $-^{c}$ & $-^{c}$ & $-^{c}$ & $-^{c}$ & 221 \\
\hline
\end{tabular}

${ }^{\mathrm{a}}$ Different types of $M$. gordonae showed different patterns that need more research in the future.

${ }^{\mathrm{b}} M$. intracellulare displayed the different patterns in our study.

${ }^{\mathrm{c}}$ Number of fragment lengths that are not identified.

${ }^{d}$ PRA: PCR-restriction fragment-length polymorphism analysis.

preliminarily provide some basic scientific data in the different species and distribution of NTM related to pulmonary disease in China, so it will be practical application and reference value for NTM pulmonary disease and tuberculosis control and cure.

\section{Additional Points}

GenBank Sequence Accession Numbers. The sequences used in the manuscript have been submitted to the GenBank sequence database recently. In the GenBank sequence database, the accession numbers of sequences are KF432417KF432429 (13 partial rpoB genes), KF432430-KF432816 (387 partial hsp65 genes), and KF432817-KF432823 (7 ITS sequences) (see Supplementary Material accession numbers).

\section{Disclosure}

The funders had no role in the study design, data collection and analysis, manuscript preparation, or decision to publish.

\section{Competing Interests}

The authors declare that they have no competing interests.

\section{Authors' Contributions}

Haican Liu, Lulu Lian, Yi Jiang, Mingxiang Huang, and Yunhong Tan contributed equally to this paper.

\section{Funding}

This work was funded by the Projects 2013ZX10003006-002001 and 2011ZX10004-001 of the National Key Program of Mega Infectious Disease.

\section{Acknowledgments}

The authors thank the staffs of the respective hospitals in the 8 provinces and autonomous regions of China for their excellent contributions to this study. They are grateful to Yuhong Tan, Chongxiang Tong, Guilian Li, Yunkai Su, Jun $\mathrm{Fu}$, Qing Wang, and Jianping Deng for providing the isolates and the patients' information.

\section{References}

[1] J. Esteban, M. García-Pedrazuela, M. C. Muñoz-Egea, and F. Alcaide, "Current treatment of nontuberculous mycobacteriosis: an update," Expert Opinion on Pharmacotherapy, vol. 13, no. 7, pp. 967-986, 2012.

[2] J. O. Falkinham III, "Surrounded by mycobacteria: nontuberculous mycobacteria in the human environment," Journal of Applied Microbiology, vol. 107, no. 2, pp. 356-367, 2009.

[3] J. O. Falkinham III, "Nontuberculous mycobacteria from household plumbing of patients with nontuberculous mycobacteria disease," Emerging Infectious Diseases, vol. 17, no. 3, pp. 419-424, 2011.

[4] J. P. Euzeby, "List of Prokaryotic names with Standing in Nomenclature-Genus Mycobacterium," 2013, http://www.bacterio.cict.fr/m/mycobacterium.html. 
[5] D. E. Griffith, T. Aksamit, B. A. Brown-Elliott et al., "An official ATS/IDSA statement: diagnosis, treatment, and prevention of nontuberculous mycobacterial diseases," American Journal of Respiratory and Critical Care Medicine, vol. 175, no. 4, pp. 367416, 2007.

[6] R. M. Thomson and W.-W. Yew, "When and how to treat pulmonary non-tuberculous mycobacterial diseases," Respirology, vol. 14, no. 1, pp. 12-26, 2009.

[7] A. Babalik, T. Kuyucu, E. N. Ordu, D. Ernam, M. Partal, and K. Köksalan, "Non-tuberculous mycobacteria infection: 75 cases," Tuberkuloz ve Toraks, vol. 60, no. 1, pp. 20-31, 2012.

[8] Z. Hmama, "Management of drug-resistant TB," in Tuberculosis-Current Issues in Diagnosis and Management, InTech, 2013, http://creativecommons.org/licenses/by/3.0.

[9] J. Hui, H. Wang, Y. Wang et al., "Prevalence of nontuberculous mycobacteria infection, China, 2004-2009," Emerging Infectious Diseases, vol. 18, no. 3, pp. 527-528, 2012.

[10] P. T. Kent and G. P. Kubica, Public Health Mycobacteriology: A Guide for the Level III Laboratory, US Department of Health and Human Services, Public Health Service, Centers for Disease Control, Atlanta, Ga, USA, 1985.

[11] M. D. Cave, K. D. Eisenach, G. Templeton et al., "Stability of DNA fingerprint pattern produced with IS6110 in strains of Mycobacterium tuberculosis," Journal of Clinical Microbiology, vol. 32, no. 1, pp. 262-266, 1994.

[12] M. G. Murray and W. F. Thompson, "Rapid isolation of high molecular weight plant DNA," Nucleic Acids Research, vol. 8, no. 19, pp. 4321-4326, 1980.

[13] R. C. Huard, L. C. De Oliveira Lazzarini, W. R. Butler, D. Van Soolingen, and J. L. Ho, "PCR-based method to differentiate the subspecies of the Mycobacterium tuberculosis complex on the basis of genomic deletions," Journal of Clinical Microbiology, vol. 41, no. 4, pp. 1637-1650, 2003.

[14] J. Whang, B. S. Lee, G.-E. Choi et al., "Polymerase chain reaction-restriction fragment length polymorphism of the rpoB gene for identification of Mycobacterium avium subsp. paratuberculosis and differentiation of Mycobacterium avium subspecies," Diagnostic Microbiology and Infectious Disease, vol. 70, no. 1, pp. 65-71, 2011.

[15] B.-J. Kim, K.-H. Lee, B.-N. Park et al., "Differentiation of mycobacterial species by PCR-restriction analysis of DNA (342 base pairs) of the RNA polymerase gene (rpoB)," Journal of Clinical Microbiology, vol. 39, no. 6, pp. 2102-2109, 2001.

[16] A. Devallois, K. S. Goh, and N. Rastogi, "Rapid identification of mycobacteria to species level by PCR-restriction fragment length polymorphism analysis of the hsp65 gene and proposition of an algorithm to differentiate 34 mycobacterial species ," Journal of Clinical Microbiology, vol. 35, no. 11, pp. 2969-2973, 1997.

[17] E. Chimara, L. Ferrazoli, S. Y. M. Ueky et al., "Reliable identification of mycobacterial species by PCR-restriction enzyme analysis (PRA)-hsp65 in a reference laboratory and elaboration of a sequence-based extended algorithm of PRA-hsp65 patterns," BMC Microbiology, vol. 8, article 48, 2008.

[18] B.-J. Kim, K.-H. Lee, B.-N. Park et al., "Differentiation of mycobacterial species by PCR-restriction analysis of DNA (342 base pairs) of the RNA polymerase gene (rpoB)," Journal of Clinical Microbiology, vol. 39, no. 6, pp. 2102-2109, 2001.

[19] A. Telenti, F. Marchesi, M. Balz, F. Bally, E. C. Bottger, and T. Bodmer, "Rapid identification of mycobacteria to the species level by polymerase chain reaction and restriction enzyme analysis," Journal of Clinical Microbiology, vol. 31, no. 2, pp. 175$178,1993$.

[20] E. E. Bodle, J. A. Cunningham, P. Della-Latta, N. W. Schluger, and L. Saiman, "Epidemiology of nontuberculous mycobacteria in patients without HIV infection, New York City," Emerging Infectious Diseases, vol. 14, no. 3, pp. 390-396, 2008.

[21] F. Brunello, M. Ligozzi, E. Cristelli, S. Bonora, E. Tortoli, and R. Fontana, "Identification of 54 mycobacterial species by PCRrestriction fragment length polymorphism analysis of the hsp65 gene," Journal of Clinical Microbiology, vol. 39, no. 8, pp. 27992806, 2001.

[22] A. da Silva Rocha, A. M. W. Barreto, C. E. Dias Campos et al., "Novel allelic variants of mycobacteria isolated in Brazil as determined by PCR-restriction enzyme analysis of hsp65," Journal of Clinical Microbiology, vol. 40, no. 11, pp. 4191-4196, 2002.

[23] W. Cheunoy, T. Prammananan, A. Chaiprasert, and S. Foongladda, "Comparative evaluation of polymerase chain reaction and restriction enzyme analysis: two amplified targets, hsp65 and rpoB, for identification of cultured mycobacteria," Diagnostic Microbiology and Infectious Disease, vol. 51, no. 3, pp. 165-171, 2005.

[24] B. Häfner, H. Haag, H.-K. Geiss, and O. Nolte, "Different molecular methods for the identification of rarely isolated non-tuberculous mycobacteria and description of new hsp65 restriction fragment length polymorphism patterns," Molecular and Cellular Probes, vol. 18, no. 1, pp. 59-65, 2004.

[25] H. Lee, H.-J. Park, S.-N. Cho, G.-H. Bai, and S.-J. Kim, "Species identification of mycobacteria by PCR-restriction fragment length polymorphism of the rpoB gene," Journal of Clinical Microbiology, vol. 38, no. 8, pp. 2966-2971, 2000.

[26] B. Imperiale, M. Zumárraga, A. Gioffré, B. Di Giulio, A. Cataldi, and N. Morcillo, "Disease caused by non-tuberculous mycobacteria: diagnostic procedures and treatment evaluation in the north of Buenos Aires province," Revista Argentina de Microbiologia, vol. 44, no. 1, pp. 3-9, 2012.

[27] T. Adékambi, P. Colson, and M. Drancourt, "rpoB-based identification of nonpigmented and late-pigmenting rapidly growing mycobacteria," Journal of Clinical Microbiology, vol. 41, no. 12, pp. 5699-5708, 2003.

[28] A. Roth, M. Fischer, M. E. Hamid, S. Michalke, W. Ludwig, and H. Mauch, "Differentiation of phylogenetically related slowly growing mycobacteria based on 16S-23S rRNA gene internal transcribed spacer sequences," Journal of Clinical Microbiology, vol. 36, no. 1, pp. 139-147, 1998.

[29] A. McNabb, D. Eisler, K. Adie et al., "Assessment of partial sequencing of the 65-kilodalton heat shock protein gene (hsp65) for routine identification of Mycobacterium species isolated from clinical sources," Journal of Clinical Microbiology, vol. 42, no. 7, pp. 3000-3011, 2004.

[30] H. D. S. P. Pedro, M. I. F. Pereira, M. D. R. A. Goloni, S. Y. M. Ueki, and E. Chimara, "Nontuberculous mycobacteria isolated in São José do Rio Preto, Brazil between 1996 and 2005," Jornal Brasileiro de Pneumologia, vol. 34, no. 11, pp. 950-955, 2008.

[31] P. M. Cassidy, K. Hedberg, A. Saulson, E. McNelly, and K. L. Winthrop, "Nontuberculous mycobacterial disease prevalence and risk factors: a changing epidemiology," Clinical Infectious Diseases, vol. 49, no. 12, pp. e124-e129, 2009.

[32] Y. Zhao, S. Xu, L. Wang et al., "National survey of drug-resistant tuberculosis in China," The New England Journal of Medicine, vol. 366, no. 23, pp. 2161-2170, 2012. 
[33] H. Shojaei, P. Heidarieh, A. Hashemi, M. M. Feizabadi, and A. D. Naser, "Species identification of neglected nontuberculous mycobacteria in a developing country," Japanese Journal of Infectious Diseases, vol. 64, pp. 265-271, 2011.

[34] S. G. Senna, J. Battilana, J. C. Costa et al., "Sequencing of hsp65 gene for identification of Mycobacterium species isolated from environmental and clinical sources in Rio de Janeiro, Brazil," Journal of Clinical Microbiology, vol. 46, no. 11, pp. 3822-3825, 2008.

[35] W. Hoefsloot, J. van Ingen, C. Andrejak et al., "The geographic diversity of nontuberculous mycobacteria isolated from pulmonary samples: an NTM-NET collaborative study," European Respiratory Journal, vol. 42, no. 6, pp. 1604-1613, 2013.

[36] M. Tsukamura, "Proposal of a new genus, Gordona, for slightly acid-fast organisms occurring in sputa of patients with pulmonary disease and in soil," Journal of General Microbiology, vol. 68 , no. 1 , pp. 15-26, 1971.

[37] F. Pourahmad, K. D. Thompson, A. Adams, and R. H. Richards, "Comparative evaluation of Polymerase Chain ReactionRestriction Enzyme Analysis (PRA) and sequencing of heat shock protein 65 (hsp65) gene for identification of aquatic mycobacteria," Journal of Microbiological Methods, vol. 76, no. 2, pp. 128-135, 2009. 

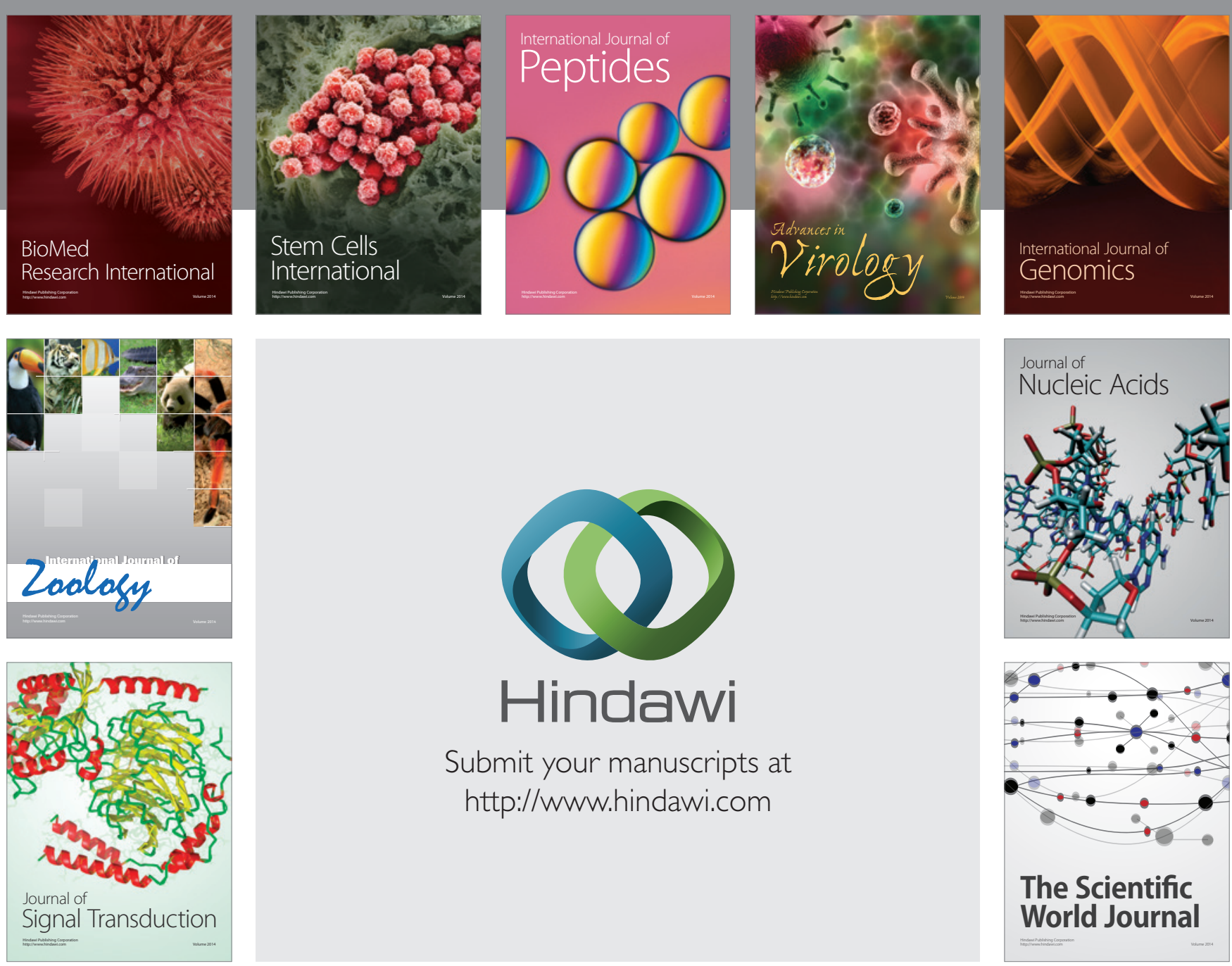

Submit your manuscripts at

http://www.hindawi.com
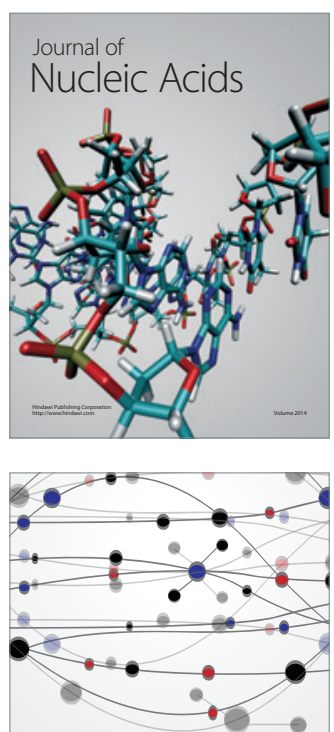

The Scientific World Journal
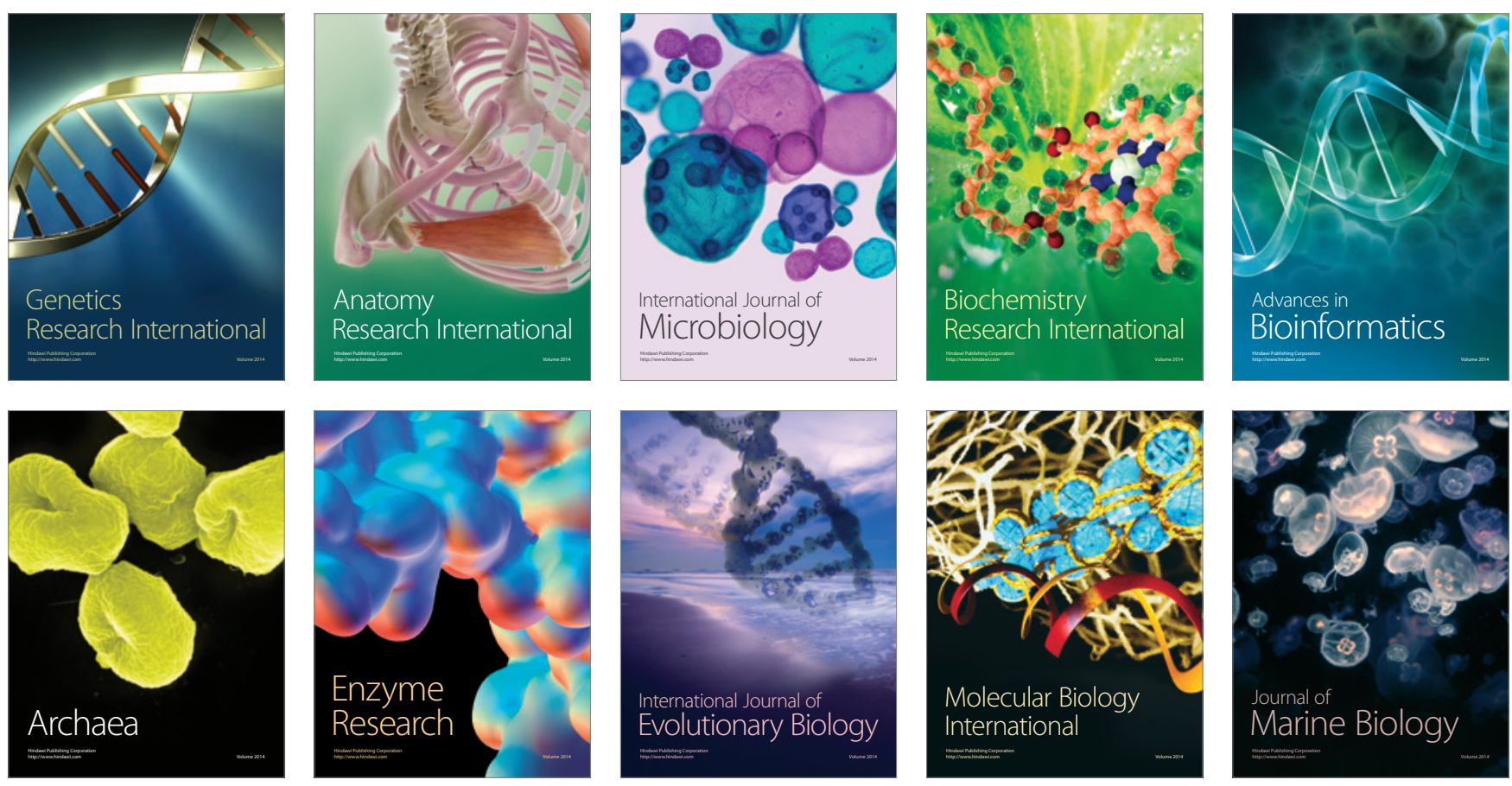